\title{
Adjusting to Global Change through Clonal Growth and Epigenetic Variation
}

\author{
Richard S. Dodd ${ }^{1 *}$ and Vladimir Douhovnikoff ${ }^{2}$ \\ ${ }^{1}$ Department of Environmental Science Policy and Management, University of California, Berkeley, Berkeley, CA, USA, \\ ${ }^{2}$ Department of Biology, Bowdoin College, Brunswick, ME, USA
}

OPEN ACCESS

Edited by:

Peter Alpert,

University of Massachusetts -

Amherst, USA

Reviewed by:

Philippe V. Baret,

Université Catholique de Louvain,

Belgium

Vit Latzel,

Institute of Botany of the Czech Academy of Sciences, Czech Republic

*Correspondence:

Richard S. Dodd

dodd@berkeley.edu

Specialty section:

This article was submitted to Agroecology and Land Use Systems, a section of the journal

Frontiers in Ecology and Evolution

Received: 24 January 2016 Accepted: 11 July 2016 Published: 26 July 2016

Citation: Dodd RS and Douhovnikoff V (2016) Adjusting to Global Change through Clonal Growth and Epigenetic Variation. Front. Ecol. Evol. 4:86. doi: 10.3389/fevo.2016.00086
The earth is experiencing major changes in global and regional climates and changes are predicted to accelerate in the future. Many species will be under considerable pressure to evolve, to migrate, or be faced with extinction. Clonal plants would appear to be at a particular disadvantage due to their limited mobility and limited capacity for adaptation. However, they have outlived previous environmental shifts and clonal species have persisted for millenia. Clonal spread offers unique ecological advantages, such as resource sharing, risk sharing, and economies of scale among ramets within genotypes. We suggest that ecological attributes of clonal plants, in tandem with variation in gene regulation through epigenetic mechanisms that facilitate and optimize phenotype variation in response to environmental change may permit them to be well suited to projected conditions.

Keywords: clonal plants, epigenetic variation, transgenerational, climate acclimation, plasticity

\section{INTRODUCTION}

Rapid and extreme climate changes are predicted, raising questions as to the capacity of plants to adjust to and survive the new environments. In clonal plants, limited dispersal and lack of recombination as a source of new gene combinations might compromise their capacity to migrate or evolve fast enough. Recent work in epigenetics has revealed an alternative path to adaptation involving variation in gene regulation, whereby genotypes can respond to environmental change without genetic recombination (Richards, 2006; Jablonka and Raz, 2009; Massicotte and Angers, 2012), that has consequences for clonal plants (Verhoeven and Preite, 2014; Douhovnikoff and Dodd, 2015). We suggest that ecological advantages to the clonal growth strategy, in tandem with epigenetically regulated accommodation through plasticity (acclimation) could position many clonal plant species well for future ecological success.

The most recent IPCC report (IPCC, 2014) predicts increasing temperatures among a range of carbon emission scenarios, with greatest changes occurring at higher latitudes and elevations. A second prediction from the IPCC report is increased frequency of extreme climatic events, such as heat, droughts, floods and storm damage. Indirect effects of these extreme events will include reduced plant defenses, increased attacks from pests and diseases and subsequent episodes of fire and soil erosion. Rates of climate change predicted by the climate models for the next century are unprecedented and may exceed by an order of magnitude the rates of climate warming during the Holocene deglaciation (Diffenbaugh and Field, 2013). The last major period of climatic change, during the Pleistocene, saw major species' distributional shifts (Hewitt, 2004), and changes in community structure as a result of unequal species' responses (Huntley, 1999). Ecologists have 
already monitored plant responses to recent climate change that include (1) colonization, as altitudinal and latitudinal displacements occur (Parmesan and Yohe, 2003) and (2) adaptation, such as spring-time advances in phenological processes (Hughes, 2000). Currently, mortality through increased attacks by pests and diseases following drought stress is putting some ecosystems at risk (Woods et al., 2005; Hicke et al., 2006). Because of the anticipated rates of climate change, population re-locations through dispersal and colonization are expected to be more successful responses than survival through adaptation in situ (Aitken et al., 2008). Community structure will likely change as species respond unequally; modeling suggests that community diversity decreases and non-analog communities are most likely to form when dispersal differences among species are high (Urban et al., 2012). Those species with limited ranges, or low dispersal potential are the most likely to face extinction.

The sedentary nature of plants imposes constraints on the velocity of response to rapidly changing environmental conditions. The potential for plants to track climate change depends on long distance dispersal events that allow colonization of new habitat and added genetic variation on the colonizing front (Kremer et al., 2012). For many clonal plants that spread vegetatively from attached organs (rhizomes, roots, stem bases), the opportunity for populations to track environmental change through long distance dispersal will be limited (Winkler and Fischer, 2002; Winkler and Stöcklin, 2002). If clonal plants are limited in their ability to disperse, will species that depend on this mode of reproduction be able to take advantage of in situ adaptation as a response to climate change? In the absence of meiotic recombination, adaptation requires fitness-beneficial mutations (mitotic recombination is unlikely to provide a sufficient source of genotypic variation that could be selectively advantageous.). Accumulation of beneficial mutations is slow and, for phenotypic traits, antagonistic interactions among traits are likely to impede adaptation (Etterson and Shaw, 2001). Nevertheless, clonal plants have persisted for thousands, or even millions of years during past environmental changes (Neiman et al., 2009), and clonal plants have been successful in colonizing new habitats (Ahmad et al., 2008; Zhang et al., 2013), occupying broad geographic ranges (Geng et al., 2007; Ganie et al., 2016) and have come to dominate some ecosystems (Hollingsworth and Bailey, 2000).

So, how do the classic paradigms for clonal plants fail to capture their ecological potential in a dynamic world? First, obligate clonality is rare in nature (Savidan, 2010). Even in extreme environments where clonal reproduction is expected to predominate (Eckert, 2002), high genetic diversity can be maintained by episodes of sexual recruitment (de Witte and Stöcklin, 2010). Second, clonal growth permits a range of advantageous ecological strategies including resource sharing (Alpert, 1990), niche specialization (Gómez and Stuefer, 2006; Louâpre et al., 2012) and rapid vegetative growth, particularly in pioneer habitats. Thirdly, plastic phenotypic responses may include an adaptive component that to some extent substitutes for, and can be far more rapid than adaptation through genetic selection (Verhoeven and Preite, 2014; Douhovnikoff and Dodd, 2015). Accommodation through plasticity has commonly been invoked as important in permitting clonal plants to respond to heterogeneous environments (Parker et al., 2003; Geng et al., 2007). Furthermore, phenotypic accommodation to changing environments ultimately can lead to evolutionary change through selection on elevations and slopes of norms of reaction (WestEberhard, 2005; Lande, 2009). Recently, an increasing number of studies have shown that plastic responses can be mediated through epigenetic modifications (Jaenisch and Bird, 2003; Richards et al., 2006), the most commonly studied being DNA methylation that results in changes in gene expression. These epigenetic marks may be stable across somatic generations (Bossdorf et al., 2008; Castonguay and Angers, 2012) and across germlines (Jablonka and Raz, 2009; Richards et al., 2012; Verhoeven and Preite, 2014; Douhovnikoff and Dodd, 2015); the latter known as transgenerational (Boyko et al., 2010). Stable epigenetic variations that result in phenotypic variation are thought to offer both short and long-term possibilities for plants to be buffered against their environment (Richards et al., 2006; Nicotra et al., 2010; Verhoeven et al., 2010; Zhang et al., 2013) and provide an alternative, or are complementary to genomic adaptations. Because epigenetic variations can be heritable and reversible (Bossdorf et al., 2008; Richards et al., 2008, 2012; Jablonka and Raz, 2009; Nicotra et al., 2010; Verhoeven and Preite, 2014; Douhovnikoff and Dodd, 2015), they offer a potentially flexible mechanism for plant adaptation. Therefore, epigenetic diversity could provide a crucial source of adaptive potential in asexual plants (Castonguay and Angers, 2012; Verhoeven and Preite, 2014; Douhovnikoff and Dodd, 2015).

Here, we provide some perspectives on the possible success of clonal plants under the predictions of future climate change. We examine how epigenetic changes and their inheritance may contribute to resilience of clonal plants under progressive climate change and climatic extremes.

\section{Colonization on the Advancing Front}

Studies of plant responses to past climate changes suggest that rare long-distance seed dispersal events have been important in facilitating population migrations (Clark et al., 2003; Petit et al., 2004). The success of these founder populations depends on the chance that suitable genotypes are among the migrant pool and that sufficient genetic diversity can rapidly be incorporated in the population (Kremer et al., 2012). The latter requires a continuous supply of migrants, or the capability of the founder individuals to support environmental conditions through phenotypic plasticity for long enough that genetic variation can accumulate (Fischer et al., 2000; Petit et al., 2003; Mimura and Aitken, 2007). Contrary to the common belief that clonal plants have low dispersal capability, elevated levels of genotypic diversity in many clonal species suggest recruitment from seedlings (Douhovnikoff et al., 2004), even at altitudinal and elevational extremes (de Witte and Stöcklin, 2010), allowing opportunities for long distance dispersal. The maintenance and growth of a population founded by a single propagule and subsequent variations in plastic response, as it accommodates to the new environment, constitutes an important ecological advantage. Two sources of epigenetic variation help founder populations to adjust. The 
first is through environmentally-induced epigenetic change and the second is through stochastic epimutations (Verhoeven and Preite, 2014).

Environmentally-induced epigenetic changes are direct responses to environmental stresses that are heritable across generations and distinct from common environmental effects such as on gametes or seeds subject to the same environment as the parent. Such effects have been shown for salt-stressed invasive knotweeds (Richards et al., 2008), environmentally-stressed dandelions (Verhoeven et al., 2010) and pathogen-infected Arabidopsis (Dowen et al., 2012). Because these epigenetic changes are likely to be directional, as long as epigenetic changes are rapid enough and are stable across generations, serial epimutations could maintain populations at the same fitness level as the environment progressively changes. High rates of methylation of cytosine at the CG position, five times greater than genetic mutations in Arabidopsis, were estimated by Ossowski et al. (2010). Although lack of stability resulting from high epimutation rates has been argued as a reason that epigenetic changes are unlikely to have long-term evolutionary consequences (Furrow, 2014), van der Graaf et al. (2015), have shown that epimutation-selection equilibria are comparable to those expected for genetic mutations, suggesting their potential role in long-term evolution. In addition, a form of midterm acclimation, the dosage regulation of genes in addition to simple activation and silencing, and reversals at different rates allows for a broad range of fine-tuned modifications (Bräutigam et al., 2013). This increased epigenetic variation permits plants to adjust to change as they encounter new conditions through space, or changing conditions over time; two highly likely circumstances for clonal plants that are often broadly distributed and long lived (Douhovnikoff and Dodd, 2015).

Stochastic epimutations can be beneficial, or deleterious, and provided that they are stable across enough generations, can be acted upon in similar ways as genetic mutations (Slatkin, 2009). Indeed, there is evidence that stochastic epimutations accumulate in a clock-like manner, resembling the accumulation of genetic mutations (Hagmann et al., 2015). Elevated levels of epimutations have been associated with environmental stress (Rapp and Wendel, 2005; Verhoeven et al., 2010) and therefore provide an important source of variation under climate change (Platt et al., 2015). For clonal plants, the higher rate of epimutations over genetic mutations offers an increased possibility for different epialleles to be selected for among ramets of the same founding genotype, permitting both spatial and temporal scales of heterogeneity to develop that may be exploited rapidly by clonal spread (Douhovnikoff and Dodd, 2015). For example, at a spatial scale, as clones forage across the landscape, ramets could become differentially specialized in the uptake of resources (Hutchings and de Kroon, 1994; Wang et al., 2011). At a temporal scale, serial epigenetic mutations can lead to a greater range of phenotypes available for response to climatic variations; high forward and backward epimutation rates leads to much greater variation in epialles than genetic alleles (van der Graaf et al., 2015).
The rapidity at which epigenetic changes can occur and their stability will confer considerable advantages to both sexual and asexual plants under rapid environmental changes, relative to the slower accumulation of genetic diversity through mutations and recombination. Is there any evidence that epigenetic variation has indeed played a role in response to climatic variations across species ranges or in response to climate changes? Preite et al. (2015) tested for a signal of DNA methylation with northward colonization following the last glaciation in apomictic dandelions. Although they failed to detect any signal that would confirm clinal epigenetic adaptation, some epigenetic variants were uncorrelated with genetic variation and may have been a source for local phenotypic adaptations. They concluded that clinal epigenetic changes may be transitory and, over long periods of time genetic adaptation would erase any epigenetic signal. In the California oak Quercus lobata, seed dispersal distances are limited and post-glacial advances have probably been over relatively short distances. Platt et al. (2015) showed significant $\mathrm{CpG}$ methylation associated with climatically distinct populations of valley oak, suggesting epigenetic adaptation, or that the epialleles were tightly linked to adaptive genes. An interesting role for epigenetics on transcriptomic variations according to clone history was reported for Populus by Raj et al. (2011). Cuttings from clonally propagated Populus trees that had been planted in different geographic locations were grown in a common environment and exposed to drought stress. Transcriptome-level patterns were paralleled by differences in genome-wide DNA methylation and were most pronounced in clones with the longest time since establishment and last common propagation. This suggests an epigenomic basis for the transcriptome variation in drought stress response associated with clone history. The synchronization of plant phenology with environmental conditions is under strong selection pressure because of the need to maximize the growing season, while minimizing the risks of cold injury (Savolainen et al., 2004) and is important in the adaptation of plants during range shifts. Epigenetic-based "memory" of environmental conditions during seed development has been shown to determine bud phenology in progeny of Picea abies (Yakovlev et al., 2011). Below normal temperatures during seed development led to earlier bud phenology and above normal temperatures led to later bud phenology. Only recently, have we begun to examine variations in epigenetic responses to environmental variations in non-model plants, but these and other examples are beginning to emerge that point to an important role that epigenetic modifications may play in plant acclimation to climatic variation.

\section{Extreme Climatic Events}

Extreme climatic events can be the most devastating for plant survival by pushing systems beyond thresholds of tolerance (Feder et al., 2000). The predicted increase in extreme events will place many organisms under stress (i.e., drought) and impose episodes of extreme environmental events (i.e., fire) and potentially devastating biotic interactions (i.e., pests and diseases). It has been suggested that extreme events may have impacts on ecosystems even before the progressive changes in temperature or rainfall (Gaines and Denny, 1993). Evolutionary 
responses to select for stress-tolerant genotypes are unlikely to be rapid enough to protect populations against extinction in the face of extreme stresses. However, the potential for epigenetic responses to stress may provide the phenotypic variation necessary to sustain populations during events that could push plants past threshold tolerance levels. We now know that environmental stresses can elicit changes in DNA methylation. Examples mostly from in vitro tests on well-studied systems such as crop plants or Arabidopsis have been reviewed by Chinnusamy and Zhu (2009). In many cases, these involve histone mediated epigenetic changes that are reversed when the environmental cue is removed. The reversibility of epigenetic changes can provide an important additional source of variation. It would be interesting to test whether reversals can provide a preadaptation to future change. In other words, once an epigenetic change has occurred, even if reversed, could it be easier for the same change to occur again in the future (a form of hormesis, Douhovnikoff and Dodd, 2015). Further studies of stress-induced DNA methylation in genetically identical apomictic dandelions revealed more than $75 \%$ of epigenetic modifications to be transmitted to offspring not exposed to the environmental stress (Verhoeven et al., 2010). These epigenetic changes may be stresstargeted or random (subject to natural selection), but in either case they contribute to the overall response to environmental stimuli and indicate an added potential for phenotypic diversity (Verhoeven and Preite, 2014).

Although the potential for stress-related epigenetic changes may occur in both sexual and asexual plants, the combination of these responses and the ecology of clonal species can explain in part the success of clonality in environments subject to severe stresses. Many species are particularly vulnerable during the seed development, germination and seedling establishment phase, particularly in drought-prone habitats. Indeed, the switch from sexual to asexual reproduction is commonly associated with the risks associated with sexual reproduction (Eckert, 2002). Clonal reproduction provides an escape from the seedling phase, coupled with rapid vegetative growth because of the existing root system. The moderating effect epigenetic variation has on reduced genetic recombination, to some extent tempers the genetic disadvantage of this sex-avoidance strategy. Increased fire frequencies and severity are expected to be the new norm in many parts of the world as a result of higher temperature and increased drought (Westerling et al., 2011; Brando et al., 2014). Although some sexual reproductive systems are fire-adapted, in a great many resprouting systems, clonal reproduction provides the most rapid recovery after fire

\section{REFERENCES}

Ahmad, R., Liow, P. S., Spencer, D. F., and Jasieniuk, M. (2008). Molecular evidence for a single genetic clone of invasive Arundo donax in the United States. Aquat. Bot. 88, 113-120. doi: 10.1016/j.aquabot.2007.08.015

Aitken, S. N., Yeaman, S., Holliday, J. A., Wang, T., and Curtis-McLane, S. (2008). Adaptation, migration or extirpation: climate change outcomes for tree population. Evol. Appl. 1, 95-111. doi: 10.1111/j.1752-4571.2007.00013.x

Alpert, P. (1990). Water sharing among ramets in a desert population of Distichlis spicata (Poaceae). Am. J. Bot. 77, 1648-1651. doi: 10.2307/2444496
(Bond and Midgley, 2001). Another effect of drought-stress is the increased incidence of disease and pest outbreaks (Woods et al., 2005; Hicke et al., 2006). The search for heritable variation in disease resistance traits usually assumes variations in DNA sequence. However, recently Latzel et al. (2012) reported the epigenetic inheritance of response to the defense hormones, jasmonic acid and salicylic acid, in Arabidopsis thaliana (Latzel et al., 2012). The role of epigenetics in plant defense to pests and diseases is an area that deserves much more attention as it seems likely to hold considerable promise in understanding disease dynamics in natural populations. The assumption that resistance is genetically based would suggest that clonal genotypes may be at a disadvantage as disease spreads through a population. However, if stress-related epimutations arise in populations, it is possible that disease outbreaks could induce defense responses regardless of the host genotype.

\section{CONCLUSIONS}

The velocity of future climate change is commonly viewed as necessitating rapid plant movements as natural selection cannot operate fast enough to generate novel beneficial gene combinations. However, the range of origins of epigenetic variation could provide phenotypic variation that would buffer against all but the most extreme climatic events. Clonal plants will continue to be an important component of ecosystems because of the attributes that they offer under heterogeneous environments, including rapid vegetative growth and multiplication, resource sharing and niche specialization among connected individuals. With our improved understanding of epigenetic systems and their mode of transmission among clonal copies and across sexual generations, we are uncovering only the superficial skin of a layer of complexity that drives phenotypic responses to the environment. The epigenome is likely to be particularly important in biological systems that lack genetic recombination, and under environmental changes, when the velocity of change exceeds the adaptation possible through natural selection. The added phenotypic diversity offered through epigenomic change should provide the buffer against environmental change that will permit more stable genetic systems to evolve.

\section{AUTHOR CONTRIBUTIONS}

$\mathrm{RD}$ and $\mathrm{VD}$ contributed equally to the ideas expressed here and to the writing of the manuscript.

Bond, W. J., and Midgley, J. M. (2001). The persistence niche: ecology of sprouting in woody plants. Trends Ecol. Evol. 16, 45-51. doi: 10.1016/S01695347(00)02033-4

Bossdorf, O., Richards, C. L., and Pigliucci, M. (2008). Epigenetics for ecologists. Ecol. Lett. 11, 106-115. doi: 10.1111/j.1461-0248.2007.01130.x

Boyko, A., Golubov, A., Bilichak, A., and Kovalchuk, I. (2010). Chlorine ions but not sodium ions alter genome stability of Arabidopsis thaliana. Plant Cell Physiol. 51, 1066-1078. doi: 10.1093/pcp/pcq048

Brando, P. M., Balch, J. K., Nepstad, D. C., Morton, D. C., Putz, F. E., Coe, M. T., et al. (2014). Abrupt increases in Amazonian tree mortality due to 
drought-fire interactions. Proc. Natl. Acad. Sci. U.S.A. 111, 6347-6352. doi: 10.1073/pnas.1305499111

Bräutigam, K., Vining, K. J., Lafon-Placette, C., Fossdal, C. G., Mirouze, M., Marcos, J. G., et al. (2013). Epigenetic regulation of adaptive responses of forest tree species to the environment. Ecol. Evol. 3, 399-415. doi: 10.1002/ ece3.461

Castonguay, E., and Angers, B. (2012). The key role of epigenetics in the persistence of asexual lineages. Genet. Res. Int. 2012:534289. doi: 10.1155/2012/534289

Chinnusamy, V., and Zhu, J. K. (2009). Epigenetic regulation of stress responses in plants. Curr. Opin. Plant Biol. 12, 133-139. doi: 10.1016/j.pbi.2008.12.006

Clark, J. S., Lewis, M., McLachlan, J. S., and HilleRisLambers, J. (2003). Estimating population spread: what can we forecast and how well? Ecology 84, 1979-1988. doi: 10.1890/01-0618

de Witte, L. C., and Stöcklin, J. (2010). Longevity of clonal plants: why it matters and how to measure it. Ann. Bot. 106, 859-870. doi: 10.1093/aob/mcq191

Diffenbaugh, N. S., and Field, C. B. (2013). Changes in ecologically critical terrestrial climate conditions. Science 341, 486-492. doi: 10.1126/science.1237 123

Douhovnikoff, V., Cheng, A., and Dodd, R. S. (2004). Incidence, size and spatial structure of clones in second growth stands of coast redwood, Sequoia sempervirens (Cupressaceae). Am. J. Bot. 91, 1140-1146. doi: 10.3732/ajb.91.7.1140

Douhovnikoff, V., and Dodd, R. S. (2015). Epigenetics: a potential mechanism for clonal plant success. Plant Ecol. 216, 227-233. doi: 10.1007/s11258-014-0430-z

Dowen, R. H., Pelizzola, M., Schmitz, R. J., Lister, R., Dowen, J. M., Nery, J. R., et al. (2012). Widespread dynamic DNA methylation in response to biotic stress. Proc. Natl. Acad. Sci. U.S.A. 109, E2183-E2191. doi: 10.1073/pnas.1209329109

Eckert, C. G. (2002). The loss of sex in clonal plants. Evol. Ecol. 15, 501-520. doi: 10.1023/A:1016005519651

Etterson, J. R., and Shaw, R. G. (2001). Constraint to adaptive evolution in response to global warming. Science 294, 151-154. doi: 10.1126/science.1063656

Feder, M. A., Benet, A. F., and Huey, R. B. (2000). Evolutionary physiology. Annu. Rev. Ecol. Syst. 31, 315-341. doi: 10.1146/annurev.ecolsys.31.1.315

Fischer, M., Husi, R., Prati, D., Peintigner, M., van Kleunen, M., and Schmid, B. (2000). RAPD variation among and within small and large populations of the rare clonal plant Ranunculus reptans (Ranunculaceae). Am. J. Bot. 87, 1128-1137. doi: 10.2307/2656649

Furrow, R. E. (2014). Epigenetic inheritance, epimutation, and the response to selection. PLoS ONE 9:e101559. doi: 10.1371/journal.pone.0101559

Gaines, S. D., and Denny, M. W. (1993). The largest, smallest, highest, lowest, longest, and shortest: extremes in ecology. Ecology 74, 1677-1692. doi: $10.2307 / 1939926$

Ganie, A. H., Reshi, Z. A., Wafai, B. A., and Puijalon, S. (2016). Clonal growth architecture and spatial dynamics of 10 species of the genus potamogeton across different habitats in Kashmir Valley, India. Hydrobiologia 767, 289-299. doi: 10.1007/s10750-015-2509-5

Geng, Y., Pan, X., Xu, C., Zhang, W. J., Li, B., Chen, J. K., et al. (2007). Phenotypic plasticity rather than locally adapted ecotypes allows the invasive alligator weed to colonize a wide range of habitats. Biol. Invasions 9, 245-256. doi: 10.1007/s10530-006-9029-1

Gómez, S., and Stuefer, J. F. (2006). Members only: induced systemic resistance to herbivory in a clonal plant network. Oecologia 147, 461-468. doi: 10.1007/s00442-005-0293-z

Hagmann, J., Becker, C., Müller, J., Stegle, O., Meyer, R. C., Wang, G., et al. (2015). Century-scale methylome stability in a recently diverged Arabidopsis thaliana lineage. PLoS Genet. 11:e1004920. doi: 10.1371/journal.pgen.1004920

Hewitt, G. M. (2004). A climate for colonization. Heredity 92, 1-2. doi: 10.1038/s.hdy. 6800365

Hicke, J. A., Logan, J. A., Powell, J., and Ojima, D.S. (2006). Changing temperatures influence suitability for modeled mountain pine beetle (Dendroctonus ponderosae) outbreaks in the western United States. J. Geophys. Res. Biogeosci. 111:G02019. doi: 10.1029/2005SJG00101

Hollingsworth, M. L., and Bailey, J. P. (2000). Evidence for massive clonal growth in the invasive weed Fallopia japonica (Japanese Knotweed). Bot. J. Linn. Soc. 133, 463-472. doi: 10.1111/j.1095-8339.2000.tb01589.x

Hughes, L. (2000). Biological consequences of global warming: is the signal already apparent? Trends Ecol. Evol. 15, 56-61. doi: 10.1016/S0169-5347(99)01764-4
Huntley, B. (1999). "Species distribution and environmental change: considerations from the site to the landscape scale," in Ecosystem Management: Questions for Science and Society, eds E. Maltby, M. Holdgate, M. Acreman, and A. Weir (Virginia Water: Royal Holloway Institute for Environmental Research), 115-130.

Hutchings, M. J., and de Kroon, H. (1994). Foraging in plants: the role of morphological plasticity in resource acquisition. Adv. Ecol. Res. 25, 159-238.

IPCC (2014). "Climate Change 2014: Synthesis Report," in Contribution of Working Groups, I, II and III to the Fifth Assessment Report of the Intergovernmental Panel on Climate Change Core Writing Team, eds R. K. Pachauri and L. A. Meyer (Geneva: IPCC).

Jablonka, E., and Raz, G. (2009). Transgenerational epigenetic inheritance: prevalence, mechanisms, and implications for the study of heredity and evolution. Q. Rev. Biol. 84, 131-176. doi: 10.1086/598822

Jaenisch, R., and Bird, A. (2003). Epigenetic regulation of gene expression: how the genome integrates intrinsic and environmental signals. Nat. Genet. 33, 245-254. doi: $10.1038 / n g 1089$

Kremer, A., Ronce, O., Robledo-Arnuncio, J. J., Guillaume, F., Bohrer, G., Nathan, R., et al. (2012). Long-distance gene flow and adaptation of forest trees to rapid climate change. Ecol. Lett. 15, 378-392. doi: 10.1111/j.1461-0248.2012.01746.x

Lande, R. (2009). Adaptation to an extraordinary environment by evolution of phenotypic plasticity and genetic assimilation. J. Evol. Biol. 22, 1435-1446. doi: 10.1111/j.1420-9101.2009.01754.x

Latzel, V., Zhang, Y., Moritz, K. K., Fischer, M., and Bossdorf, O. (2012). Epigenetic variation in plant responses to defence hormones. Ann. Bot. 110, 1423-1428. doi: $10.1093 / \mathrm{aob} / \mathrm{mcs} 088$

Louâpre, P., Bittebière, A.-K., Clément, B., Pierre, J.-S., and Mony, C. (2012). How past and present influence the foraging of clonal plants? PLoS ONE 7:e38288. doi: 10.1371/journal.pone.0038288

Massicotte, R., and Angers, B. (2012). General-purpose genotype or how epigenetics extend the flexibility of a genotype. Genet. Res. Int. 2012:317175. doi: $10.1155 / 2012 / 317175$

Mimura, M., and Aitken, S. N. (2007). Adaptive gradients and isolation-bydistance with postglacial migration in Picea sitchensis. Heredity 99, 22-24. doi: 10.1038/sj.hdy. 6800987

Neiman, M., Meirmans, S., and Meirmans, P. G. (2009). What can asexual lineage age tell us about the maintenance of sex? Ann. N. Y. Acad. Sci. 1168, 185- 200. doi: 10.1111/j.1749-6632.2009.04572.x

Nicotra, A. B., Atkin, O. K., Bonser, S. P., Davidson, A. M., Finnegan, E. J., Mathesius, U., et al. (2010). Plant phenotypic plasticity in a changing climate. Trends Plant Sci. 15, 684-692. doi: 10.1016/j.tplants.2010.09.008

Ossowski, S., Schneeberger, K., Lucas-Lledo, J. I., Warthmann, N., Clark, R. M., Shaw, R. G., et al. (2010). The rate and molecular spectrum of spontaneous mutations in Arabidopsis thaliana. Science 327, 92-94. doi: 10.1126/science. 1180677

Parker, I. M., Rodriguez, J., and Loik, M. E. (2003). An evolutionary approach to understanding the biology of invasions: local adaptation and general-purpose genotypes in the weed Verbascum thapsus. Conserv. Biol. 17, 59-72. doi: 10.1046/j.1523-1739.2003.02019.x

Parmesan, C., and Yohe, G. (2003). A globally coherent fingerprint of climate change impacts across natural systems. Nature 421, 37-42. doi: 10.1038 /nature01286

Petit, R. J., Aguinagalde, I., de Beaulieu, J. L., Bittkau, C., Brewer, S., Cheddadi, R., et al. (2003). Glacial refugia: hotspots but not melting pots of genetic diversity. Science 300, 1563-1565. doi: 10.1126/science.1083264

Petit, R. J., Bialozyt, R., Garnier-Gere, P., and Hampe, A. (2004). Ecology and genetics of tree invasions: from recent introductions to Quaternary migrations. Forest Ecol. Manag. 197, 117-137. doi: 10.1016/j.foreco.2004.05.009

Platt, A., Gugger, P. F., Pellegrini, M., and Sork, V. L. (2015). Genome-wide signature of local adaptation linked to variable $\mathrm{CpG}$ methylation in oak populations. Mol. Ecol. 24, 3823-3830. doi: 10.1111/mec.13230

Preite, V., Snoek, L. B., Oplaat, C., Biere, A., Van der Putten, W. H., and Verhoeven, K. J. F. (2015). The epigenetic footprint of poleward range-expanding plants in apomictic dandelions. Mol. Ecol. 24, 4406-4418. doi: 10.1111/mec.13329

Raj, S., Bräutigam, K., Hamanishi, E., T., Wilkins, O., Schroeder, W., Mansfield, S., D., et al. (2011). Clone history shapes Populus drought responses. Proc. Natl Acad. Sci. U.S.A. 108, 12521-12526. doi: 10.1073/pnas.1103341108 
Rapp, R. A., and Wendel, J. F. (2005). Epigenetics and plant evolution. New Phytol. 168, 81-91. doi: 10.1111/j.1469-8137.2005.01491.x

Richards, C. L., Bossdorf, O., Muth, N. Z., Gurevitch, J., and Pigliucci, M. (2006). Jack of all trades, master of some? On the role of phenotypic plasticity in plant invasions. Ecol. Lett. 9, 981-993. doi: 10.1111/j.1461-0248.2006.0 0950.x

Richards, C. L., Schrey, A. W., and Pigliucci, M. (2012). Invasion of diverse habitats by few Japanese knotweed genotypes is correlated with epigenetic differentiation. Ecol. Lett. 15, 1016-1025. doi: 10.1111/j.14610248.2012.01824.x

Richards, C. L., Walls, R. L., Bailey, J. P., Parameswaran, R., George, T., and Pigliucci,. M. (2008). Plasticity in salt tolerance traits allows for invasion of novel habitat by Japanese knotweed s. l. (Fallopia japonica and Fbohemica, Polygonaceae). Am. J. Bot. 95, 931-942. doi: 10.3732/ajb.20 07364

Richards, E. J. (2006). Inherited epigenetic variation-revisiting soft inheritance. Nat. Rev. Genet. 7, 395-401. doi: 10.1038/nrg1834

Savidan, Y. (2010). Apomixis: genetics and breeding. Plant Breed. Rev. 18, 13-86. doi: 10.1002/9780470650158.ch2

Savolainen, O., Bokma, F., García-Gil, M. R., Komulainen, P., and Repo, T. (2004). Genetic variation in cessation of growth and frost hardiness and consequences for adaptation of Pinus sylvestris to climatic changes. Forest Ecol. Manag. 197, 79-89. doi: 10.1016/j.foreco.2004.05.006

Slatkin, M. (2009). Epigenetic inheritance and the missing heritability problem. Genetics 182, 845-850. doi: 10.1534/genetics.109.102798

Urban, M. C., Tewksbury, J. J., and Sheldon, K. S. (2012). On a collision course: competition and dispersal differences create no-analogue communities and cause extinctions during climate change. Proc. Biol. Sci. 279, 2072-2080. doi: 10.1098/rspb.2011.2367

van der Graaf, A., Wardenaar, R., Neumann, D. A., Taudt, A., Shaw, R. G., Jansen, R. C., et al. (2015). Rate, spectrum, and evolutionary dynamics of spontaneous epimutations. Proc. Natl. Acad. Sci. U.S.A. 112, 6676-6681. doi: $10.1073 /$ pnas. 1424254112

Verhoeven, K. J. F., Jansen, J. J., Van Dijk, P. J., and Biere, A. (2010). Stress induced DNA methylation changes and their heritability in asexual dandelions. New Phytol. 185, 1108-1118. doi: 10.1111/j.1469-8137.2009.03121.x

Verhoeven, K. J. F., and Preite, V. (2014). Epigenetic variation in asexually reproducing organisms. Evolution 68, 644-655. doi: 10.1111/evo.12320
Wang, W. S., Pan, Y. J., Zhao, X. Q., Dwivedi, D., Zhu, L. H., Ali, J., et al. (2011). Drought-induced site-specific DNA methylation and its association with drought tolerance in rice (Oryza sativa L.). J. Exp. Bot. 62, 1951-1960. doi: $10.1093 /$ jxb/erq391

West-Eberhard, M. J. (2005). Phenotypic accommodation: adaptive innovation due to developmental plasticity. J. Exp. Zool. B304, 610-618. doi: 10.1002/jez.b.21071

Westerling, A. L., Turner, M. G., Smithwick, E. A. H., Romme, W. H., and Ryan, M. G. (2011). Continued warming could transform Greater Yellowstone fire regimes by mid-21st century. Proc. Natl. Acad. Sci. U.S.A. 108, 13165-13170. doi: $10.1073 /$ pnas.1110199108

Winkler, E., and Fischer, M. (2002). The role of vegetative spread and seed dispersal for optimal life histories of clonal plants: a simulation study, Evol. Ecol. 15: 281-301. doi: 10.1023/A:1016080714200

Winkler, E., and Stöcklin, J. (2002). Sexual and vegetative reproduction of Hieracium pilosella L. under competition and disturbance: a grid-based simulation model. Ann. Bot. 89, 525-536. doi: 10.1093/aob/mcf075

Woods, A., Coates, K. D., and Hamann,. A. (2005). Is an unprecedented dothistroma needle blight epidemic related to climate change? Bioscience 55, 761-769. doi: 10.1641/0006-3568(2005)055[0761:IAUDNB]2.0.CO;2

Yakovlev, I. A., Asante, D. K. A., Fossdal, C. G., Junttila, O., and Johnsen, $\varnothing$. (2011). Differential gene expression related to an epigenetic memory affecting climatic adaptation in Norway spruce. Plant Sci. 180, 132-139. doi: 10.1016/j.plantsci.2010.07.004

Zhang, Y. Y., Fischer, M., Colot, V., and Bossdorf, O. (2013). Epigenetic variation creates potential for evolution of plant phenotypic plasticity. New Phytol. 197, 314-322. doi: 10.1111/nph.12010

Conflict of Interest Statement: The authors declare that the research was conducted in the absence of any commercial or financial relationships that could be construed as a potential conflict of interest.

Copyright (c) 2016 Dodd and Douhovnikoff. This is an open-access article distributed under the terms of the Creative Commons Attribution License (CC BY). The use, distribution or reproduction in other forums is permitted, provided the original author(s) or licensor are credited and that the original publication in this journal is cited, in accordance with accepted academic practice. No use, distribution or reproduction is permitted which does not comply with these terms. 